\title{
Skull Sexual Monomorphism in the Gwembe Dwarf Goat Breed from Zambia
}

\author{
Parés-Casanova $\mathrm{PM}^{\star 1}$, Kataba $\mathrm{A}^{2}$, Mwaanga $\mathrm{ES}^{2}$ and Simukoko $\mathrm{H}^{2}$ \\ ${ }^{1}$ Department of Animal Production, University of Lleida, Av. Alcalde Rovira Roure, Lleida, Catalunya, Spain \\ ${ }^{2}$ Department of Biomedical Sciences, University of Zambia, School of Veterinary Medicine, Lusaka, Zambia
}

*Corresponding author: Parés-Casanova PM, Department of Animal Production, University of Lleida, Av. Alcalde Rovira Roure 191, E-25198 Lleida, Catalunya, Spain, E-mail: peremiquelp@prodan.udl.cat

Citation: Parés-Casanova PM, Kataba A, Mwaanga ES, Simukoko H (2014) Skull Sexual Monorphism in the Gwembe Dwarf Goat Breed from Zambia. J Vet Sci Anim Husb 2(3): 301. doi: 10.157444/2348-9790.1.504

Received Date: May 31, 2014 Accepted Date: October 20, 2014 Published Date: October 21, 2014

\begin{abstract}
This study involved some morphometric parameters of the skull of thirty adult Gwembe Dwarf Goats (15 males and 15 females) without any apparent skeletal disorders. Lower jaws were not included in this study. A total of 43 linear measurements were analyzed. The analysis reflected no differences between sexes, thereby indicating lack of general conformation differences between males and females. However, comparison of the parameters that exhibited most variance revealed that horncore basal circumference and length of the horn core on the front margin were strongly influenced by sex. Therefore, only the horn conformation could be used as discriminator sexual variable. This result couples with the fact that males usually have stronger and larger horns than females but skull size seeming no to be very different between sexes. The obtained results would indicate a marked sexual monomorphism in this breed.
\end{abstract}

Keywords: Capra hircus; Craniometry; Sexual dimorphism; Skull biometry

\section{Introduction}

Local goat has great genetic resource potential that can be utilized as a source of superior breeding formulation adaptable to local conditions. [1] Reported that breeds of local livestock are important and should be protected because of their ability to survive under low-quality feed, unfavourable local climatic conditions, and their high resistance to local diseases and parasites. These abilities are critical in cross-breeding ventures aimed at sustaining genetic pools that have evolved through centuries within the given locality.

Phenotypic and morphological characteristics are still commonly used by researchers and practitioners in characterization of animals' breeds [2]. The Gwembe Dwarf Goat or locally known as "Mpongo" is a small breed with average weight of $35 \mathrm{~kg}$ for both males and females found in the Gwembe valley in Southern Province of Zambia. Well-adapted to hot and dry climatic conditions with low rainfall patterns, this breed is of multi colour coat variations ranging from completely black, brown, black and white, grey to white and brown- with horns of medium size and usually curved backwards (http://dad.fao.org/). Other goat breeds of Zambia include the Plateau Goat located on the plateau regions of Southern Province, the Sinazongwe district of the Southern and North part of the Gwembe Valley, and the imported Boer and Saanen (http://dad.fao.org/). The morphologic and morphometric studies of the head region do not only reflect contributions of genetic and environmental components to individual development, but describe genetic and ecophenotypic variation [3]. Until now, there have been numerous comparative morphological studies of the skull anatomy in many of the mammalian species. In particular, in small ruminants the morphological structures and geometrical measurements of the skull bones have been examined to detect the distinguishing features of these species $[4]$ and breeds $[3,5,6]$. To the best knowledge of the authors, there is no published data on the morphometric parameters of the head region applied anatomy in the Zambian native goats. An exception of this is the thesis by [7], which does not contain detailed information on head conformation other than the head length and width for male and female goats of unknown breed. Moreover, complete comparative studies between sexes are not available.

So, the morphometric values of the skull of the Gwembe Dwarf Goat will not only be of ethnological importance but they will undoubtedly aid to better the description of sexual differences. Furthermore, the obtained results will provide important baseline data for further comparative studies on the skull of the Zambian native goat breeds.

\section{Materials and Methods}

Thirty dry skulls of adult Gwembe Dwarf Goat specimens aged 18 months and older were collected from five different local farms and studied. The age was determined on the basis of the growth of the third molar tooth [8]. All specimens used for this study showed no cranial deformities or bony injuries. The total series included all specimens collected. 
The method described by [9] was used for assessing cranial (neuro- and viscerocranium) linear measurements, and it is commonly used in other osteometric studies [10]. A total of 43 linear measurements were analyzed (Table 1). Lower jaws were not included in this study. Basic descriptive statistics were calculated for all samples and no size adjustment was applied. The measurements were performed using $0.1 \mathrm{~mm}$ callipers and an ovinometer. All measurements were taken by the same person (Kataba).

\begin{tabular}{|c|c|}
\hline Parameter & Definition \\
\hline 1 & Total length of the skull: the distance between akrokranion-prosthion \\
\hline 2 & Condylobasal length: caudal border of occipital condyles-prosthion \\
\hline 3 & Total length of the cranial base: basion-prosthion \\
\hline 4 & Short skull length: basion-premolare \\
\hline 5 & Premolare-prosthion length \\
\hline 7 & Upper length of the viscerocranium: nasion-prosthion \\
\hline 8 & Median frontal length: akrokranion-nasion \\
\hline 9 & Akrokranion-bregma length \\
\hline 10 & Frontal length: bregma-nasion \\
\hline 11 & Upper neurocranium length: akrokranion-supraorbitale \\
\hline 12 & Facial length: supraorbitale-prosthion \\
\hline 13 & Akrokranion-infraorbitale length \\
\hline 14 & $\begin{array}{l}\text { Greatest length of the lacrimal bone: most lateral point of the lacrimal bone -most rostral point of the } \\
\text { lacrimomaxillary suture }\end{array}$ \\
\hline 15 & Greatest length of the nasal bone: nasion-rhinion \\
\hline 16 & Entorbitale-prosthion length \\
\hline 17 & Distance between the caudal border of one occipital condyle and the infraorbitale of the same side \\
\hline 18 & Dental length: postdentale-prosthion \\
\hline 19 & Oral palatal length: palatinoorale-prosthion \\
\hline 20 & Lateral length of the premaxilla: nasointermaxillare-prosthion \\
\hline 21 & Length of the maxillary tooth row \\
\hline 22 & Length of the upper molar row \\
\hline 23 & Length of the upper premolar row \\
\hline 24 & Greatest inner width of the orbit: ectorbitale-entorbitale \\
\hline 25 & Greatest inner height of the orbit \\
\hline 26 & Greatest mastoid breadth: otion-otion \\
\hline 27 & Greatest breadth of the occipital condyles \\
\hline 28 & Greatest breadth at the bases of the paracondylar processes \\
\hline 29 & Greatest breadth of the foramen magnum \\
\hline 30 & Height of the foramen magnum: basion-opisthion \\
\hline 31 & Least breadth of parietal \\
\hline 32 & Greatest breadth between the lateral borders of horn core base \\
\hline 33 & Greatest neurocranium breadth: euryon-euryon \\
\hline 34 & Greatest frontal breadth: ectorbitale-ectorbitale \\
\hline 35 & Least breadth between the orbits: entorbitale-entorbitale \\
\hline 36 & Facial breadth: between facial tuberosities \\
\hline 37 & Greatest breadth across the nasal bones \\
\hline 38 & Greatest breadth across the premaxilla \\
\hline 39 & Greatest palatal breadth \\
\hline 40 & Horncore basal circumference \\
\hline 41 & Greatest diameter of horn core base \\
\hline 42 & Least diameter of horn core base \\
\hline 43 & Length of the horn core on the front margin \\
\hline 44 & Distance between horn tips \\
\hline
\end{tabular}

Table 1: Studied parameters (nomenclature according to Von den Driesch, 1976). A total of 43 linear measurements were analyzed. Von den Driesch's numeration has been served, except for var. 44 which is ours. 
Main simple descriptive statistics (range, mean, standard deviation and coefficient of variation) were obtained, as well the to assess normality of distribution of data in both sexes. The non-parametric one-way NPMANOVA test (Non-Parametric MANOVA, also known as PERMANOVA) was applied, using the Mahalanobis distance [11]. The significance was computed by permutation of group membership, with 9,999 replicates. Given the large number of parameters, a selection of the most relevant parameters was ultimately made using a multivariate analysis of principal components (PCA). The principal components (PC) were extracted from the co-variance matrix. The eigenanalysis was carried out on the group means ("between-group", i.e. the items analysed are the groups, not the specimens). The loadings within the individual eigenvectors for each PC were used to form contrasts in order to describe the skulls numerically. A one-way MANOVA (Multivariate ANalysis Of VAriance) tested whether male and female samples had the same mean for the most discriminant parameters. The two-sample Hotelling's $\mathrm{T}^{2}$ test was avoided as some of these parameter were non parametric. In order to identify and measure the associations among the two sets of parameters, a Canonical Correspondence Analysis was done, according to [12] and the two-tailed non-parametric U Mann-Whitney was used to test whether the medians of samples (males and females) were different.

The data recorded were analyzed statistically in customary fashion using PAST ${ }^{\circledast}$ (v. 2.17c) software. Level confidence was stablished at $5 \%$.

\section{Results}

In Table 2 there appear the main descriptive statistics for linear measurements. The NPMANOVA reflected no differences between sexes $(\mathrm{F}=1.104, \mathrm{p}=0.317)$, so it can be supposed that there appeared no general conformation differences between males and females.

\begin{tabular}{|c|c|c|c|c|c|c|c|c|c|c|c|c|c|c|}
\hline \multicolumn{8}{|c|}{ 우 } & \multicolumn{7}{|c|}{$\hat{\sigma}$} \\
\hline Var. & Min & Max & $\mathbf{X}$ & StD & $\mathrm{CV}$ & W & $\mathbf{P}$ & Min & Max & $\mathbf{X}$ & StD & $\mathrm{CV}$ & W & $\mathbf{P}$ \\
\hline 1 & 13.0 & 16.7 & 15.1 & 1.319 & 8.7 & 0.908 & 0.125 & 13.4 & 16.7 & 15.0 & 0.858 & 5.7 & 0.944 & 0.438 \\
\hline 2 & 12.6 & 16.4 & 14.3 & 1.389 & 9.7 & 0.897 & 0.085 & 12.5 & 15.8 & 14.7 & 0.746 & 5.1 & 0.801 & 0.004 \\
\hline 3 & 11.8 & 14.5 & 13.1 & 0.786 & 6.0 & 0.969 & 0.839 & 11.6 & 14.1 & 12.6 & 0.757 & 6.0 & 0.953 & 0.573 \\
\hline 4 & 7.7 & 10.3 & 9.1 & 0.789 & 8.7 & 0.963 & 0.742 & 7.5 & 10.3 & 8.2 & 0.685 & 8.3 & 0.783 & 0.002 \\
\hline 5 & 3.5 & 4.6 & 4.0 & 0.348 & 8.6 & 0.956 & 0.622 & 3.5 & 4.3 & 4.0 & 0.254 & 6.4 & 0.951 & 0.541 \\
\hline 7 & 7.8 & 9.8 & 8.6 & 0.669 & 7.8 & 0.921 & 0.198 & 7.5 & 9.4 & 8.5 & 0.534 & 6.3 & 0.974 & 0.917 \\
\hline 8 & 7.7 & 10.0 & 9.1 & 0.680 & 7.5 & 0.946 & 0.464 & 7.8 & 9.8 & 8.6 & 0.536 & 6.2 & 0.939 & 0.365 \\
\hline 9 & 4.6 & 5.3 & 5.0 & 0.197 & 3.9 & 0.951 & 0.533 & 4.3 & 5.2 & 4.9 & 0.246 & 5.0 & 0.924 & 0.218 \\
\hline 10 & 5.3 & 6.4 & 5.9 & 0.340 & 5.8 & 0.967 & 0.815 & 5.3 & 6.6 & 6.0 & 0.369 & 6.1 & 0.947 & 0.484 \\
\hline 11 & 8.2 & 9.3 & 8.9 & 0.342 & 3.8 & 0.888 & 0.063 & 8.0 & 10.0 & 9.1 & 0.711 & 7.8 & 0.928 & 0.251 \\
\hline 12 & 9.0 & 10.6 & 9.8 & 0.403 & 4.1 & 0.981 & 0.976 & 8.4 & 10.3 & 9.5 & 0.563 & 5.9 & 0.93 & 0.269 \\
\hline 13 & 9.9 & 12.0 & 10.6 & 0.615 & 5.8 & 0.923 & 0.213 & 10.0 & 11.5 & 10.7 & 0.443 & 4.1 & 0.931 & 0.285 \\
\hline 14 & 1.9 & 3.3 & 2.6 & 0.369 & 14.2 & 0.991 & 1.000 & 2.0 & 2.9 & 2.6 & 0.218 & 8.5 & 0.948 & 0.491 \\
\hline 15 & 3.9 & 5.6 & 4.8 & 0.556 & 11.7 & 0.943 & 0.422 & 4.0 & 5.5 & 4.6 & 0.411 & 9.0 & 0.889 & 0.065 \\
\hline 16 & 7.5 & 9.9 & 8.8 & 0.739 & 8.4 & 0.966 & 0.791 & 7.7 & 9.7 & 8.9 & 0.578 & 6.5 & 0.959 & 0.671 \\
\hline 17 & 10.1 & 11.9 & 11.0 & 0.658 & 6.0 & 0.928 & 0.251 & 9.9 & 11.8 & 11.1 & 0.525 & 4.7 & 0.94 & 0.383 \\
\hline 18 & 6.9 & 8.7 & 7.9 & 0.588 & 7.4 & 0.923 & 0.212 & 6.6 & 8.5 & 7.6 & 0.467 & 6.1 & 0.981 & 0.976 \\
\hline 19 & 5.7 & 6.8 & 6.2 & 0.371 & 5.9 & 0.854 & 0.020 & 5.1 & 6.5 & 6.0 & 0.377 & 6.3 & 0.947 & 0.484 \\
\hline 20 & 5.1 & 6.3 & 5.6 & 0.439 & 7.8 & 0.849 & 0.017 & 4.7 & 6.0 & 5.5 & 0.401 & 7.3 & 0.936 & 0.333 \\
\hline 21 & 4.3 & 5.6 & 5.0 & 0.449 & 9.0 & 0.918 & 0.180 & 4.1 & 5.3 & 4.6 & 0.388 & 8.5 & 0.887 & 0.060 \\
\hline 22 & 2.5 & 3.1 & 2.8 & 0.149 & 5.2 & 0.926 & 0.237 & 2.6 & 2.9 & 2.8 & 0.097 & 3.5 & 0.903 & 0.107 \\
\hline 23 & 1.5 & 2.7 & 2.2 & 0.443 & 20.5 & 0.873 & 0.038 & 1.4 & 2.5 & 1.9 & 0.403 & 20.7 & 0.887 & 0.060 \\
\hline 24 & 2.8 & 3.3 & 3.1 & 0.171 & 5.5 & 0.952 & 0.556 & 2.8 & 3.4 & 3.1 & 0.188 & 6.0 & 0.934 & 0.314 \\
\hline 25 & 2.9 & 3.2 & 3.1 & 0.093 & 3.0 & 0.944 & 0.429 & 2.8 & 3.4 & 3.2 & 0.167 & 5.3 & 0.981 & 0.973 \\
\hline 26 & 5.4 & 6.2 & 5.9 & 0.223 & 3.8 & 0.884 & 0.055 & 5.2 & 6.2 & 5.8 & 0.308 & 5.3 & 0.924 & 0.218 \\
\hline 27 & 3.8 & 4.4 & 4.1 & 0.168 & 4.1 & 0.942 & 0.402 & 4.0 & 4.3 & 4.1 & 0.087 & 2.1 & 0.92 & 0.192 \\
\hline 28 & 4.8 & 5.9 & 5.3 & 0.251 & 4.7 & 0.954 & 0.589 & 5.0 & 5.7 & 5.3 & 0.177 & 3.3 & 0.95 & 0.522 \\
\hline 29 & 1.6 & 2.0 & 1.9 & 0.106 & 5.7 & 0.973 & 0.897 & 1.5 & 2.0 & 1.8 & 0.136 & 7.5 & 0.913 & 0.151 \\
\hline 30 & 1.5 & 1.8 & 1.6 & 0.093 & 5.7 & 0.93 & 0.269 & 1.4 & 1.7 & 1.6 & 0.105 & 6.6 & 0.936 & 0.331 \\
\hline 31 & 2.2 & 3.9 & 2.9 & 0.430 & 14.7 & 0.952 & 0.556 & 2.7 & 3.7 & 3.1 & 0.318 & 10.1 & 0.946 & 0.461 \\
\hline
\end{tabular}




\begin{tabular}{|c|c|c|c|c|c|c|c|c|c|c|c|c|c|c|}
\hline \multicolumn{8}{|c|}{ 우 } & \multicolumn{7}{|c|}{$\hat{0}$} \\
\hline Var. & Min & Max & $\mathbf{X}$ & StD & CV & W & $\mathbf{P}$ & Min & $\operatorname{Max}$ & $\mathbf{X}$ & StD & CV & W & $\mathbf{P}$ \\
\hline 32 & 5.5 & 7.2 & 6.4 & 0.416 & 6.5 & 0.981 & 0.976 & 6.2 & 7.1 & 6.8 & 0.276 & 4.1 & 0.928 & 0.256 \\
\hline 33 & 5.6 & 6.6 & 5.9 & 0.264 & 4.5 & 0.795 & 0.003 & 5.4 & 6.0 & 5.8 & 0.191 & 3.3 & 0.95 & 0.524 \\
\hline 34 & 7.3 & 9.1 & 8.2 & 0.485 & 5.9 & 0.936 & 0.331 & 7.6 & 8.5 & 8.1 & 0.283 & 3.5 & 0.942 & 0.413 \\
\hline 35 & 5.4 & 7.3 & 6.4 & 0.479 & 7.5 & 0.975 & 0.922 & 5.7 & 6.9 & 6.3 & 0.272 & 4.3 & 0.949 & 0.511 \\
\hline 36 & 5.0 & 6.1 & 5.6 & 0.333 & 5.9 & 0.938 & 0.357 & 5.1 & 6.0 & 5.6 & 0.244 & 4.4 & 0.982 & 0.979 \\
\hline 37 & 1.6 & 2.5 & 2.1 & 0.237 & 11.1 & 0.983 & 0.984 & 1.7 & 2.4 & 2.1 & 0.232 & 11.2 & 0.944 & 0.433 \\
\hline 38 & 1.7 & 2.3 & 2.1 & 0.189 & 9.0 & 0.905 & 0.112 & 1.7 & 2.3 & 2.1 & 0.151 & 7.1 & 0.961 & 0.716 \\
\hline 39 & 5.0 & 5.9 & 5.5 & 0.275 & 5.0 & 0.963 & 0.747 & 5.0 & 5.9 & 5.4 & 0.246 & 4.5 & 0.979 & 0.959 \\
\hline 40 & 0.0 & 8.0 & 6.4 & 1.954 & 30.5 & 0.672 & 0.000 & 6.8 & 9.0 & 8.2 & 0.615 & 7.5 & 0.94 & 0.382 \\
\hline 41 & 1.8 & 2.9 & 2.4 & 0.328 & 13.8 & 0.962 & 0.732 & 2.2 & 3.2 & 2.8 & 0.260 & 9.3 & 0.982 & 0.982 \\
\hline 42 & 1.5 & 2.1 & 1.9 & 0.208 & 11.2 & 0.897 & 0.085 & 1.9 & 2.5 & 2.1 & 0.169 & 7.9 & 0.905 & 0.114 \\
\hline 43 & 0.0 & 6.8 & 4.9 & 1.611 & 33.1 & 0.817 & 0.006 & 4.5 & 8.4 & 6.0 & 1.089 & 18.2 & 0.928 & 0.251 \\
\hline 44 & 4.5 & 7.9 & 5.9 & 0.939 & 15.9 & 0.968 & 0.830 & 6.0 & 8.9 & 7.0 & 0.748 & 10.7 & 0.881 & 0.048 \\
\hline
\end{tabular}

$\mathrm{X}$ : average

StD: Standard Deviation

CV: Coefficient of Variation (\%)

W: Shapiro-Wilk

Table 2: Main descriptive statistics for linear measurements (expressed in $\mathrm{mm}$ ) for females ( 우, $\mathrm{n}=15)$ and males $(\hat{\jmath}, \mathrm{n}=15)$.

Von den Driesch's numeration has been served, except for var. 44 which is ours. Not normally distributed data appear in bold.

For the PCA, first 6 PCs presented a eigenvalue higher of Jollife cut-off's one (0.363). PC1 explained a 43\% of variance (Table 3). The most important parameters that entered into the PC1 were 40 (horncore basal circumference) and 43 (length of the horn core on the front margin), both related to horns, and into the PC2 was 40. For PC3 was the parameter 4 (short skull length), which presented the highest value (Table 4). For these parameters, NPMANOVA did reflect differences between sexes $(\mathrm{F}=4.752$, $\mathrm{p}=0.006$ ), so sexual dimorphism can be suspected not for a general skull form but only for horns. Horn parameters that had strong influence on the sex were precisely the length of the horn core on the front margin (1.239, Can 1$)$ and the horncore basal circumference $(-0.935$, Can 1$)$ (Figure 1), the latter one (but not the former) $(U=65.5, p=0.053)$ being statistically different between sexes $(\mathrm{U}=20.5, \mathrm{p}<0.001)$ (Figure 2$)$.

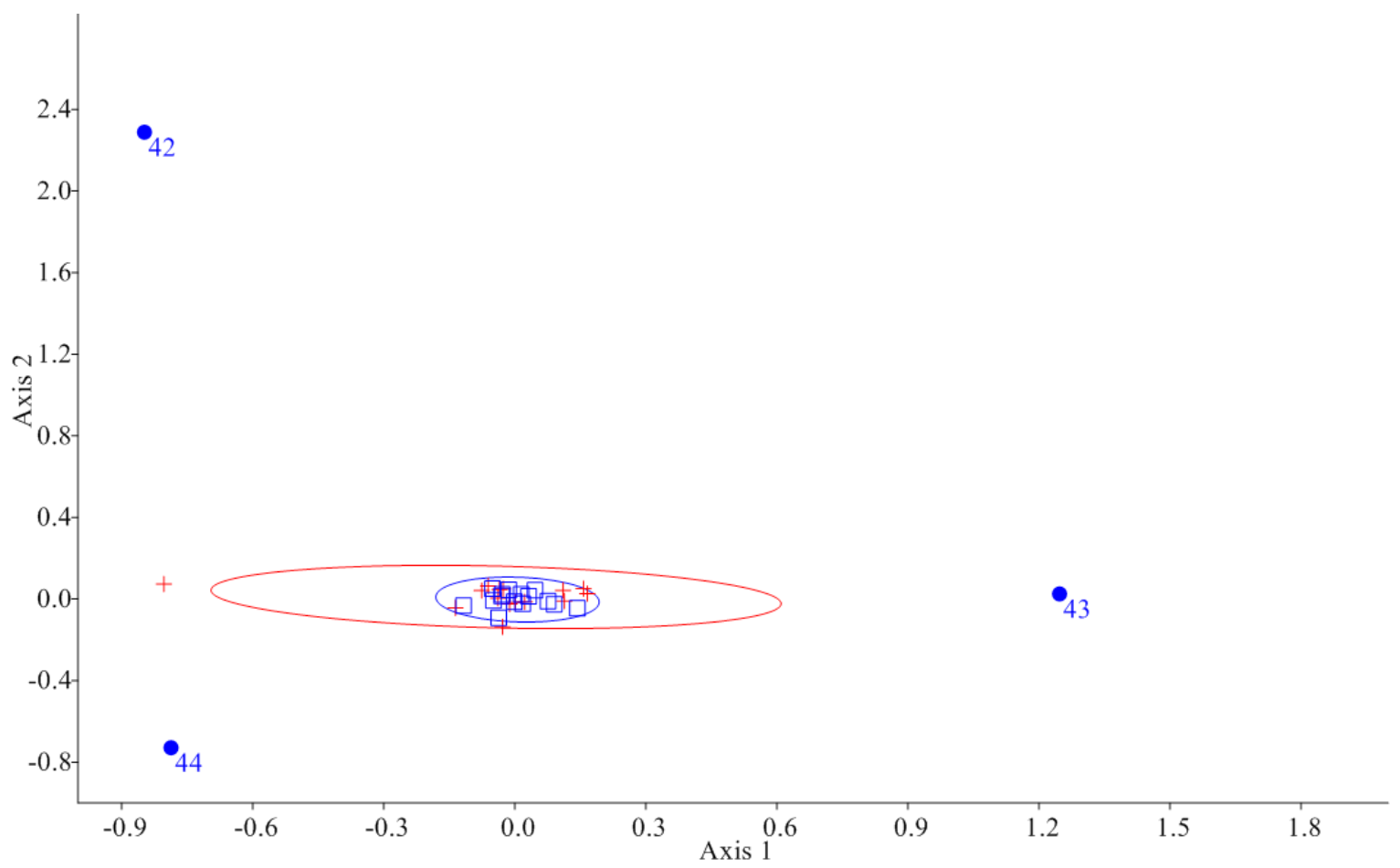

Figure 1: Canonical Analysis for horn parameters (95\% confidence ellipses), showing the position of individuals according to their horn conformation (squares for males, $n=15$, crosses for females, $n=15$ ). Number on dots show each analyzed parameter (42: least diameter of horn core base; 43 : length of the horn core on the front margin; 44: distance between horn tips). 


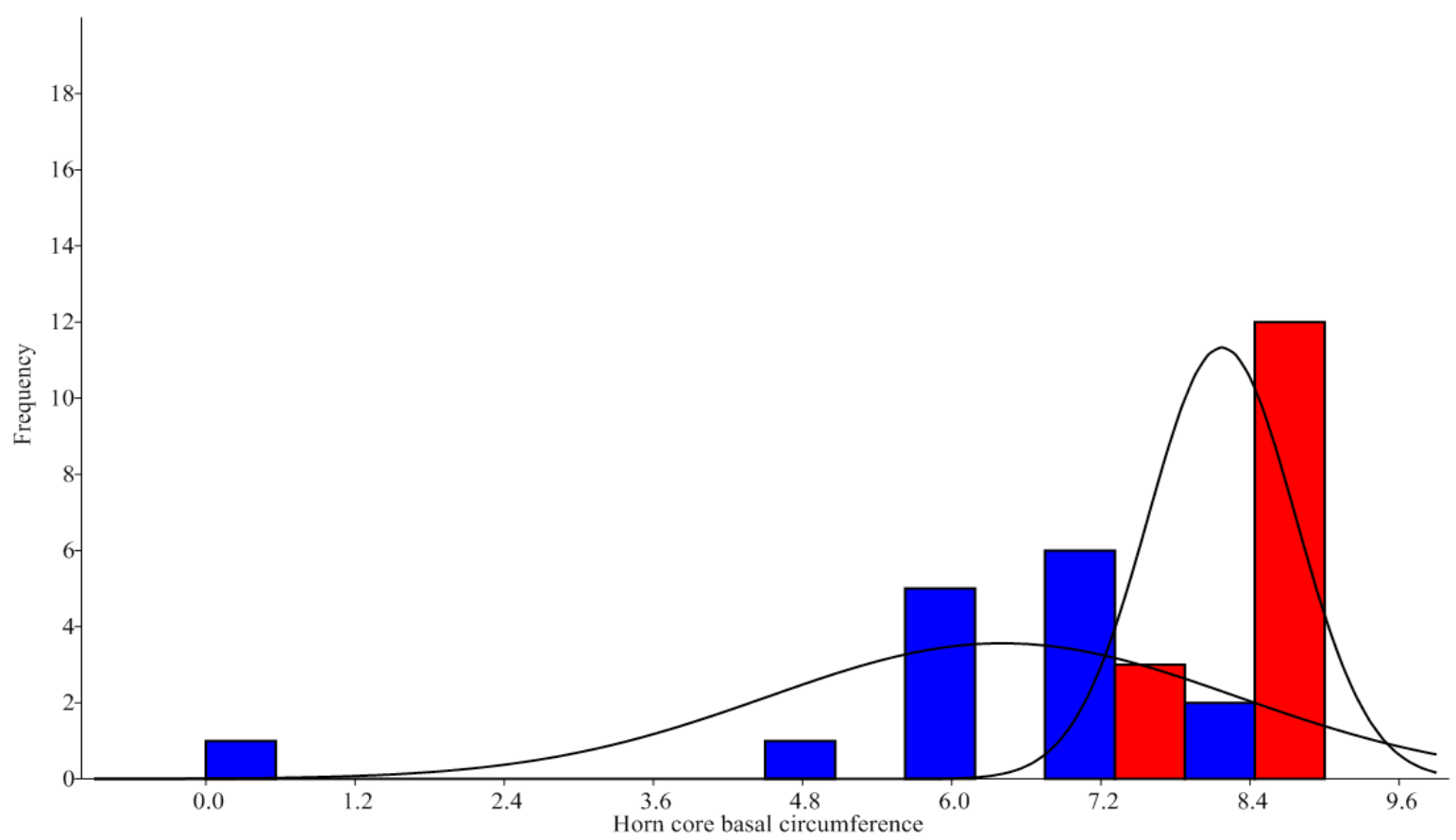

Figure 2: Histogram of horncores basal circumferences for males (right, $n=15$ ) and females (left, $n=15$ ). This parameter that shows statistically differences between sexes (Mann-Whitney's $U=20.5, p<0.001$ ).

\begin{tabular}{|c|c|c|c|}
\hline Pc & Eigenvalue & \% variance & \% total explained \\
\hline 1 & 6.486 & 43.042 & 43.042 \\
\hline 2 & 3.422 & 22.705 & 65.747 \\
\hline 3 & 1.369 & 9.085 & 74.832 \\
\hline 4 & 0.925 & 6.141 & 80.973 \\
\hline 5 & 0.691 & 4.586 & 85.559 \\
\hline 6 & 0.390 & 2.589 & 88.148 \\
\hline
\end{tabular}

Table 3: Eigenvalues and \% variances for first 6 Principal Components (PCs). Jollife cut-off $=0.363$.

\begin{tabular}{|c|c|c|c|}
\hline & PC1 & PC2 & PC3 \\
\hline 1 & 0.263 & 0.359 & -0.330 \\
\hline 2 & 0.337 & 0.282 & -0.325 \\
\hline 3 & 0.110 & 0.295 & 0.335 \\
\hline 4 & 0.012 & 0.281 & $\mathbf{0 . 4 9 8}$ \\
\hline 5 & 0.048 & 0.108 & -0.080 \\
\hline 7 & 0.106 & 0.143 & 0.161 \\
\hline 8 & -0.051 & 0.133 & 0.331 \\
\hline 9 & 0.018 & 0.033 & 0.034 \\
\hline 10 & 0.064 & 0.034 & -0.092 \\
\hline 11 & 0.042 & -0.056 & 0.301 \\
\hline 12 & 0.061 & 0.111 & 0.171 \\
\hline 13 & 0.145 & 0.091 & -0.097 \\
\hline 14 & 0.064 & 0.090 & 0.007 \\
\hline 15 & 0.093 & 0.127 & 0.005 \\
\hline 16 & 0.144 & 0.153 & -0.189 \\
\hline 17 & 0.181 & 0.116 & 0.031 \\
\hline 18 & 0.124 & 0.214 & 0.027 \\
\hline & & & \\
\hline
\end{tabular}




\begin{tabular}{|c|c|c|c|}
\hline & PC1 & PC2 & PC3 \\
\hline 19 & 0.069 & 0.164 & 0.013 \\
\hline 20 & 0.094 & 0.121 & 0.038 \\
\hline 21 & 0.062 & 0.142 & 0.091 \\
\hline 22 & -0.001 & 0.027 & -0.002 \\
\hline 23 & 0.062 & 0.112 & 0.004 \\
\hline 24 & 0.033 & 0.040 & -0.065 \\
\hline 25 & 0.015 & -0.004 & 0.069 \\
\hline 26 & 0.023 & 0.061 & 0.027 \\
\hline 27 & 0.013 & -0.002 & -0.010 \\
\hline 28 & 0.035 & 0.051 & -0.001 \\
\hline 29 & -0.016 & 0.002 & -0.002 \\
\hline 30 & -0.017 & 0.002 & -0.011 \\
\hline 31 & -0.043 & -0.098 & -0.131 \\
\hline 32 & 0.090 & -0.050 & 0.032 \\
\hline 33 & 0.023 & 0.038 & -0.031 \\
\hline 34 & 0.045 & 0.130 & 0.011 \\
\hline 35 & 0.082 & 0.125 & 0.049 \\
\hline 36 & 0.057 & 0.094 & -0.004 \\
\hline 37 & 0.013 & 0.039 & 0.037 \\
\hline 38 & 0.025 & 0.025 & 0.003 \\
\hline 39 & 0.055 & 0.083 & 0.053 \\
\hline 40 & $\mathbf{0 . 5 4 1}$ & $-\mathbf{0 . 4 3 9}$ & 0.091 \\
\hline 41 & 0.072 & -0.113 & 0.132 \\
\hline 42 & 0.043 & -0.047 & -0.038 \\
\hline 43 & $\mathbf{0 . 5 0 6}$ & -0.252 & 0.092 \\
\hline 44 & 0.264 & -0.161 & 0.159 \\
\hline & & & \\
\hline 25
\end{tabular}

Table 4: Component loading for each parameter for first 3 Principal Component (PC), which explained the $75 \%$ of the total observed variance. Highest absolute values for each component appear in bold.

\section{Discussion}

Dimorphism means two forms "sexual dimorphism" means that the two sexes of a species differ in external appearance or other features. Males and females may differ in size, color, shape, the development of appendages (such as horns, teeth, feathers, or fins), and also in scent or sound production. Species in which male and females are identical in appearance or other features are said to be "monomorphic". Our results showed that there are no general skull conformation differences between males and females in the Dwarf Zambian Goat, although some particular parameters have an strong influence on the breed sex, such as the length of the horn core on the front margin, the distance between horn tips, and the short skull length. This is in line with the fact that males usually have stronger and larger horns than females [8]. Short skull length (parameter 4) has low influence, so size seems not to be very different between sexes. According to [7] 2009, males and females would differ by their head width, not by their head length, but, as earlier stated, his research is not clearly focused on Dwarf goat.

The global variation between sexes may be interpreted in relation to extensive management styles of the animals that are moreover under a low anthropogenic influence so they tend to reinforce the natural sexual size dimorphism of the species. Thus, horn conformation could be used as discriminator sexual variable and this fact can be attributed to that sexual dimorphism in this breed is not related to differences in the diet of the two sexes but probably to participation in fighting between males, or to a mere artificial selection of males towards bigger horns by farmers.

\section{References}

1. Food and Agriculture Organization (2007) Global Plan of Action for Animal Genetic resources and Interlaken Declaration on Animal Genetic Resources, Rome, Italy.

2. Batubara A, Noor RR, Farajallah A, Tiesnamurti B, Doloksaribu M (2011) Morphometric and phylogenic analysis of six population Indonesian local goats. J Ani Sci Tech 34: 165-74.

3. Monfared AL, Naji H, Sheibani MT (2013) Applied Anatomy of the Head Region of the Iranian Native Goats (Capra Hircus). Global Vet 10: 60-4. 
4. Onuk B, Kabak M, Atalar K (2013) Anatomic and craniometric factors in differentiating roe deer (Capreolus capreolus) from sheep (Ovis aries) and goat (Capra hircus) skulls. Arch Biol Sci 65: 133-41.

5. Sarma K (2006) Morphological and Craniometrical Studies on the Skull of Kagani Goat (Capra hircus) of Jammu Region. Int J Morphol 24 : $449-55$.

6. Shawulu JC, Kwari HD, Olopade JO (2011) Morphology of the bones of the skull in the Sahel ecotypes of goats (Capra hircus) in Nigeria. J Vet Anat 4: 1-13.

7. Ahmadu B (2001) Management Practices, Morphometric Body Measurements and Diseases of Local Zambian Goats. Ph. Thesis. The University of Zambia, Lusaka, Zambia.

8. Dyce KM, Sack WO, Wensing CJG (2002) Textbook of Veterinary Anatomy (3 ${ }^{\text {rd }}$ edn) Saunders Publishers, Philadelphia, USA.

9. Driesch A Von den (1976) A Guide to the Measurement of Animal Bones from Archaelogical sites. Peabody Museum Press, Massachusetts, USA.

10. Onar V, Belli O, Owen PR (2005) Morphometric Examination of Red Fox (Vulpes vulpes) from the Van-Yoncatepe Necropolis in Eastern Anatolia. Int J Morphol 23: 253-60.

11. Anderson MJ (2001) A new method for non-parametric multivariate analysis of variance. Austral Ecology 26: $32-46$.

12. Legendre P, Legendre L (1998) Numerical Ecology ( $2^{\text {nd }}$ edn) Elsevier Publications, Oxford, UK.

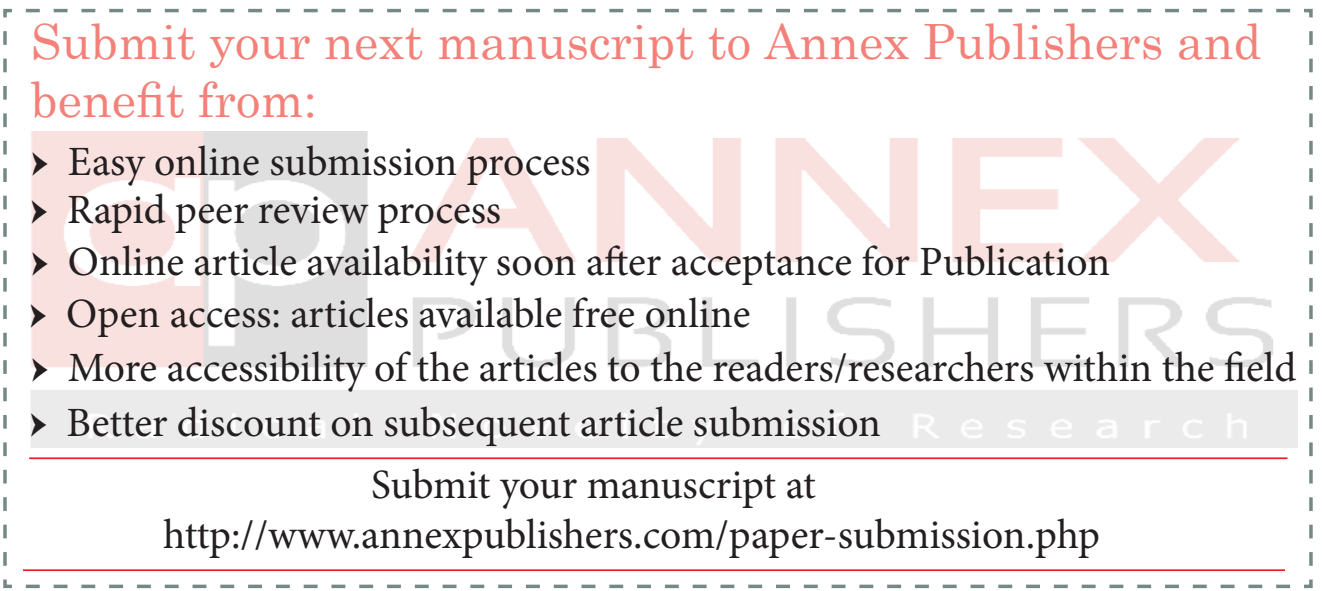

